\title{
Analyzing Open Source Business with Porter's Five Forces
}

\author{
Alireza Amrollahi and Babak Akhgar
}

\begin{abstract}
Today many IT companies (in both commercial and non-profit sectors) use Open Source as their main infrastructure, and as consequence they face to some social, cultural and financial aspects of OS. Now a day, the use of open source software in IT businesses, and in the IT market is going to become popular and accepted. In this paper we try to make a strategic analysis of OS business model by using the Porter's five forces framework. We study many case studies and previous researches for this analysis and recognize that the issue of license and revenue model has to be precisely considered while a firm adopts the open source strategy.
\end{abstract}

Index Terms-Open source, strategic analysis, five forces.

\section{INTRODUCTION}

Open Source (OS) software is defined by open source initiative as a class of software which allows the user to have access to the source code of the software, having the right and capability to use the software as they see suitable, modify the software in order to create derived works, and redistribute the derivative software free of charge, or at a charge. [1]

In recent years, the Open Source Software (OSS) development has caused a rapid shift from a model which is driven purely by communities of developers and applications (supported mainly by the academic milieu), toward commercial environment. And as a result many software companies have adopted OSS-based business strategies. OSS has attracted new SMEs which provide products and services by using OS infrastructures. The more important point is that OSS has also reshaped and modified the business models and strategies of some international large firms. As an instance, the main industrial players like IBM, Oracle, Philips, Nokia, and SAP, which have chosen to integrate OSS applications into their R\&D activities, core products, and services [2]. Emergence of open source software has also made a significant change in the IT literature, and especially after the success of many OS projects, a lot of attention has been paid to this subject in academic and professional reviews.

By the Porter's definition of strategy: "a broad based formula for how business is going to compete, what its goals should be, and what policies will be needed to carry out those goals. The essence of formulating competitive strategy is relating a company to its environment." [3], formulating the strategy is necessary for each business. And therefore study of strategy is essential for the three different categories of OS

Manuscript received June12, 2012; revised July 9, 2012.

A. Amrollahi is with the Faculty of Management, University of Tehran, Iran (e-mail: a.amrollahi@ut.ac.ir).

B. Akhgar is with the Communication and Computing Research Centre Sheffield Hallam University, UK (e-mail: b.akhgar@shu.ac.uk). stake holders:

1) IT businesses which are producers of OS products

2) OS foundations

3) Businesses which use OS as their strategic information system

In fact the OS model is not a unique model, and companies which want to adopt OS strategy can choose their business model from lots of OS or hybrid models.[4] Krishnamurthy suggests the following 4 models in OS environment: the distributor, the software producer (Non-GPL model), the software producer (GPL model) and the third-party service provider [5]. Open source initiative also defines 4 different business models for businesses that use OS, which are: support sellers, Loss leader, widget frosting, and accessorizing [6].

Carbone (2007) defines a 6 stages model for OS businesses. These six stages are: deny (stage 0), use, contribute, champion, collaborate and redefine. He also suggests that the profit of the firm would increase by the evolution of OS involvement through theses stages [7].

West (2003) has profoundly investigates different models -as well as risks and opportunities which are related to each specific used model- through case studies of three major IT companies in the late 1990s (IBM, Apple, Sun). KOSKI (2005) has studied many Finnish companies in order to explore the choices of product and license types by them. She concludes that firms that focus on the provision of services tend to supply their products under OSS licenses, whereas firms owned by a family or individuals tend to rely on traditional proprietary software in their product selection [8]. Later, Harison \& Koski (2010) more deeply differentiated OS and non-OS firms with focus on the supply strategy and concluded that smaller and more service-oriented companies tend to base their software supply strategies on OSS. They also find that market entrants have largely driven the OSS adoption, but there are no significant age-related differences in the adoption behavior of incumbent software firms [2].

However, after year 2008 some authors mentioned doubts about OS business models. The 451 group in a research about OS businesses, reports that the line between closed and open source has blurred as FOSS is embedded in proprietary products and commercial extensions have been added to OS. The report also acclaims that half of the vendors assessed in the report are combining code developed via open source projects with software developed out-of-sight of open source project members. It concludes that "open source is not a business model" and advises the vendors to pay more attention to their licensing and revenue decisions and make their business strategies more clear for their customers [9].

In this study we focus on firms which use OS 
infrastructure, and by using previous surveys and case studies, try to categorize options for these firms through a strategic model.

The aim of this strategic analysis is to help the OS companies to stay competitive in their industry. As Porter remarks, by ignoring strategy many companies have undermined structure of their industries, hastened competitive convergence, and reduced the likelihood that they or anyone else will gain a competitive advantage [10]. So the results would help firms' leaders make better decisions in regard to migrate their strategic systems to OS and more efficiently manage opportunity and risks of their OS firm.

So far many models and frameworks have been developed for strategic analysis and implementation. Akhgar (2010) has categorized 28 of them due to their application in strategy lifecycle (Analysis, Choose, Implementation, and Evaluation). [11] For the purpose of this article we have chosen Five Forces Analysis. The model clarifies an industry's fundamental attractiveness, exposes the underlying drivers of average industry profitability and provides insight into how profitability will evolve in the future [10]. The following reasons also support using the technique:

1) Its ability for both strategic analysis and strategic choice

2) Its old and frequent usage (since 1985 and almost in every resource in the field of strategic management)

3) Its frequent usage in literature of Information Systems as a strategic tool

4) Its adaptability in different industries (service, production, etc.)

We have especially benchmarked Porter's phenomenal work "Strategy and the Internet" [10] which is a source of strategic analysis for businesses which want to use Internet as a business model.

\section{Open SOURCE AND COMPETITIVE AdvantAgE}

Arrival of OS as a business model and a software have had effects on many firms. The range of this effect may be from small and midsize consulting or manufacturing enterprises to IT producers who use OS languages for developing their products.

As Porter (2001) remarks in his work - strategy and the internet - the strength of the five forces varies considerably from industry to industry, but examination of wide range of industries can help us to arrive in a long term conclusion about impact of these forces. As it has been mentioned above, OS can be seen in a wide variety of firms in different working fields, but in this study our focus is on the user side which is: firms that provide IT products and services by using OS infrastructure or use it as their strategic information systems.

\section{A. Barriers to Entry}

Existing firms within an industry often try to reduce the threat of new entrants to the marketplace by erecting barriers to entry [12]. Michael Porter mentions six major sources of barriers to entry which are: Economies of scale, Product differentiation, Capital requirements, Cost disadvantages independent of size, Access to distribution channels and Government policy [3].

By reduction in the investment cost, OS model has a significant effect on barriers to entry. New enterprises do not need to invest on infrastructure. But the transformation is something more than a change in sources of investment, and it is not just an elimination of cost: companies that till now, have just simply bought software and other infrastructures using the producer services for installation and support, now have to employ their own knowledge workers to adapt OS infrastructure in their business.

Chesbrough (2007) has compared revenue and costs of OS and proprietary software development. He mentioned market revenue and internal development cost for proprietary development but internal and external development cost and 4 different sources of revenue including: market revenue, license, spinoff and sale/divest. He also believes that OS model can bring cost and time saving (from leveraging external development) as well as new revenues for businesses [13].

On the other hand, MacAulay (2010) draws attention to the fact that benefits of OS make customers and investors nervous and this kind of feeling is usually greater when addressing start-ups and Entrepreneurs [14]. West (2003) suggests that when it is possible, a firm prefers proprietary platform strategies, because they provide better barriers of imitation and better margins. But this strategy may only be available for one or two market leaders. [4]

\section{B. Bargaining Power of Channels / Customers}

In a strategic analysis, buyers can be viewed as a competitive threat when they are in a position to demand lower prices from the company or when they demand better service (which can increase operating costs) [15]. Porter refers to different groups of customers as powerful buyers: large volume buyers, buyers of standard products who can easily find alternative suppliers, ones who use our products as a significant component of their product, ones who earn low profit and tend to diminish their purchasing costs, and finally those who consider our product unimportant or producible by themselves [3].

As you may see here, the powerful buyers exist in any business and the IT is not an exception. By using OS software as a cost reduction weapon in the price war, it can be well utilized for satisfying powerful buyers. On the other hand, the quality of OS system has been considered over the proprietary system (with same dimensions) in many cases [16-, 17- \&18]. Even Raymond (1999) remarks that indirect user benefit of open source systems has increased reliability through the concurrent debugging efforts of a widely distributed community of user-programmers [19]. And Paulson, Succi, \& Eberlein (2004) suggest that OS development often encourages creativity, and can find and fix defects more quickly compared to proprietary software [20].

Open source can also affect bargaining power of customers through switching cost. Switching costs can be any aspect of a buyer's purchasing decision that decreases the likelihood of switching his or her purchase to a competitor [12]. As switching cost goes up, customers' bargaining 
power falls and the barriers to entry into an industry rise [10]. OS platforms can have a significant effect on switching cost. Switching costs can be minimized if switching software does not necessitate switching platforms [21]. West (2003) concludes from the case of IBM that open source inherently reduces barriers to entry by rivals and switching costs of customers [4].

Conversely switching cost is not only related to monetary or technical issues. Sharma \& Patterson (2000) have shown the impact of trust on switching cost and - although no empirical evidence is available - trust in open source communities seems to be more in relation to other communities [22].

OS makes additional communication channels available, including more informal ones consulted by the target developer community [23]. This communication channels could be transformed to new distribution channels for OS and OS-based products. Also distribution of OS software would make new opportunity for producers of related stuff. IBM's vice president of management information software believes that expanding the OS software market expands the market for high-value IBM middleware, hardware, and services. He thinks that this expansion will especially create new business opportunities in areas such as embedded database applications, small business solutions, and Java and Webbased applications [24].

Some OS software is only applicable on OS platforms (like Linux/Unix). This property (which has been changed in many new OS products) may increase the switching costs for customers, as well as facing them with difficulties to accept and use the software.

\section{Bargaining Power of Suppliers}

Suppliers can be viewed as a threat when they are able to force up the price that a company must pay for its inputs, or when reduce the quality of the inputs which they supply, thereby depressing the company's profitability [15]. According to Porter there are five groups of powerful suppliers: supplier with few competitors, producers of unique or differentiated products, and ones who do not obliged to contend with other products for sale to the Industry, ones who pose a credible threat of integrating forward into the industry's business, and when we are not an important customer of the company [3].

The Internet and Information Systems provide customers with wide range of suppliers and better tools in order to control their price and quality [12]. While OS software are usually available through internet and directories like sourceforge.net or freshmeat.net with users' ranks and opinions, choosing the best solution is much more easy and it may cause a significant decrease in the power of suppliers.

Here the usual power of suppliers - which was traditionally exerted by the power of price - has been eliminated and firms are able to choose their desirable infrastructure freely from a wide range of available OS ones and customize it as the most suitable in their job, while many business users of OS in some cases only try to accelerate OS projects by monetary or technical support. West (2003) has listed many contributions of Apple, IBM and Sun between 1995 and 2002. [4]

Some other companies have suggested new meanings for product. Red Hat for example has grown up the business by customizing and providing training and support services for users of OS. The knowledge based nature of OS infrastructure has differentiated these services and made these suppliers very powerful.

\section{Threats of Substitute Product or Services}

The next force in Porter's model is the threats of substitute product. Substitute products are those of industries that serve consumers' needs in a way that is similar to those being served by the industry being analyzed [15]. Porter (1997) believes that substitute products that deserve the most attention strategically are those that: (a) are subject to trends improving their price-performance trade-off with the industry's product, or (b) those which are produced by industries earning high profits.

Another factor that should be considered is the possibility of reusing the source code. There may be pieces of code that are not designed to be used in multiple contexts that can be cannibalized or used in unexpected ways [23]. The Reuse of source codes may significantly reduce time and cost of development and bring a competitive advantage to users of OS infrastructure while competing with others.

License type is another important factor. If your license does not permit proprietary use of the OS (like GPL and LGPL), the treat of quick reuse of the code is a main drawback of using OS infrastructure. Even if the license permits you to provide your product or service in a proprietary form, the open nature of the infrastructure may let others to be aware of the modules easily and develop the same product with the same free infrastructure before you can completely strengthen your position in the market.

\section{E. Rivalry Among Existing Competitors}

The last Porter's competitive force is the extent of rivalry among established companies within an industry. If this rivalry is weak, companies have an opportunity to raise prices and earn greater profits. The extent of rivalry among established companies within an industry is largely a function of three factors:

1) The industry competitive structure,

2) Demand conditions

3) The height of exit barriers inside of the industry [15]

Porter adds some detail items such as: number of competitors, industry growth, differentiation or switching cost of product, etc. [3]. Intense rivalry in an industry assures that competitors respond quickly to any strategic actions [12].

The common challenge for the three companies: Apple, IBM and Sun in late 1990s which forced them to choose an open strategy, was the competitive force of Microsoft (especially its Windows operating system) [4].

Using the OS model itself is not a competitive advantage since it is available and can be used by everyone, but the way it is used and related services are the main advantage for companies. The response of leading industry firms varied up on whether they had used software as a source of competitive advantage, or they had retained other sources of competitive advantage [4].

Rival firms in the software industry often try to influence 
on consumers' expectations about the installation base of their product. When users choose OSS, their knowledge about the existing installation base affects their expectations about their future installation base, as a result it plays a critical role on their decision for downloading and possibly use the OSS [1].

The potential ability to provide customized products is the other advantage of OS platforms. The manager of "Apple Mac OS X" project which was developed with an OS core, remarks needs of specialized networking customers in universities as a catalyst for their OS strategy:

"We realized that the pieces they're most interested in are the most commoditized. There wasn't any proprietary technology added that we had to worry about them copying" [4].

High competitive pressures also sometimes prevent IT companies to choose open strategy for their products. The quote by Sun's CEO represents this point:

'I can't license all of Sun's intellectual property under the GPL, because it just won't work. I don't see any reason why I should give somebody who is doing commercial reuse unfettered access to stuff that cost me millions of dollars to do. We're spending over a billion dollars a year in research. I can't just throw it all on the street..." [4]

Company's contributions to the source software may be a very important intellectual asset and releasing them can be a nice present for rivals in a high competitive environment.

\section{CONCLUSION}

Understanding the opportunities and risks of the OS business models would help businesses to formulate their strategy. In this paper we used "Porter's Five Forces" model for analyzing this possibility. We used many former case studies, researches and notes in order to reach to a beneficial conclusion.

Due to the above mentioned points firms can formulate numerous strategies by choosing their model from a series of OS business models, but still they have to pay attention to some considerations, for example in case of implementing an OS business model they should be careful and considerate about the license type and potential revenue model which is predictable from each license. Both renowned corporation and entrepreneur SMEs can benefit from these models, but the structure and characteristics of competition is different for these two groups.

Today many firms have adopted different forms of OS models and the OS itself cannot be mentioned as a source of competitive advantage. But the strategies and ways that a firm uses OS are considered as competitive advantage.

\section{REFERENCES}

[1] C. Subramaniam, R. Sen, and M. Nelson, "Determinants of open source software project success: A longitudinal study," Decision Support Systems, vol. 46, no. 2, pp. 576- 585, Jan. 2009.

[2] E. Harison and H. Koski, "Applying open innovation in business strategies: Evidence from Finnish software firms," Research Policy, vol. 39, no. 3, pp. 351-359, April 2010

[3] M. Porter, "How Competitive Forces Shape Strategy," Harvard Business Review, vol. 57, no. 2, pp. 40-50, March 1979.
[4] J. West, "How open is open enough? Melding proprietary and open source platform strategies," Research Policy, vol. 32, no. 7, pp. $1259-1285$, July 2003.

[5] S. Krishnamurthy. (2003). An Analysis of Open Source Business Models. [Online]. Available: http://www.ssrn.com/abstract=650001

[6] Open source initiative. (2011). Open Source Case for Business:Advocacy. [Online]. Available: http://www.opensource.org/advocacy/case_for_business.php.

[7] P. Carbone. (2007). Competitive Open Source. [Online]. Available: http://www.osbr.ca/ojs/index.php/osbr/article/view/351/312.

[8] H. Koski, "OSS production and licensing strategies of software firms," Review of economic research on copyright issues, vol. 2, no. 2, pp. 111-125, 2005.

[9] The 451 group. (2008). Open Source is not a Business Model. [Online] Available:

http://www.blogs.the451 group.com/opensource/2008/10/13/open-sou rce-is-not-a-business-model/

[10] M. Porter, "Strategy and the Internet," Harvard Business Review, vol. 79, no. 3, pp. 40-52, March 2001.

[11] B. Akhgar, Strategic Information Systesm, 1st ed. Tehran : Negahe Danesh, 2010, ch 1.

[12] E. Pearlson and S. Saunders, Managing and using information Systems: A Strategic Approach, New York: John Wiley \& Sons, Inc., 2006, ch 4.

[2] H. Chesbrough, "Why Companies Should Have Open Business Models," MIT Sloan Management Review, vol. 48, no. 2, pp. 22-28, Winter 2007.

[13] M. MacAulay. (2010). The Business of Open: Common Pitfalls for Open Source Startups. [Online]. Available: http://www.osbr.ca/ojs/index.php/osbr/article/view/1038/997.

[14] C. Hill and J. Greth, Strategic Management: An Integrated Approach, 2nd ed, New York: Houghton Mifflin Company, 1998, ch. 3.

[15] M. Godfrey, and T. Qiang, "Evolution in Open Source Software: A Case Study," in Proc. IEEE, International Conference on Software Maintenance (ICSM'O0), Washington, 2000, pp. 131-136.

[16] T. Halloran and W. Scherlis, "High Quality and Open Source Software Practices," in. Proc. of the 2nd ICSE Workshop on Open Source, Pittsburgh, 2002, pp. 1-3.

[17] J. Kuan, "Open Source Software as Lead User's Make or Buy Decision: A Study of Open and Closed Source Quality," in. Proc. of open source software : economics, law and policy, Toulouse, France, 2002, 1-39.

[18] E. S. Raymond, The Cathedral and the Bazaar: Musings on Linux and Open Source by an Accidental Revolutionary, Cambridge: O'Reilly, 1999, ch. 1.

[19] J. W. Paulson, G. Succi, and A. Eberlein, "An empirical study of open-source and closed-source software products", Transactions on Software Engineering. IEEE, vol. 30, no. 4, pp. 246-256, April 2004.

[20] B. Behlendorf, Open Source as a Business Strategy. C. DiBona, S. Ockman and M. Stone, Voices from the Open Source Revolution, Sebastopol : O'Reilly, 1999, pp. 149-170.

[21] N. Sharma and P. Patterson, "Switching costs, alternative attractiveness and experience as moderators of relationship commitment in professional, consumer services," International Journal of Service Industry Management, vol. 11, no. 5,pp. 470-490, 2000.

[22] R. Goldman, and R. Gabriel, Innovation Happens Elsewhere: Open Source as Business Strategy, Morgan Kaufmann Publishers, 2004, ch. 4.

[23] D. Strok, "Open Source Business Models: Ready for Prime Time," IEEE SOFTWARE, vol. 22, no. 6, pp. 98-100, Nov.-Dec. 2005.

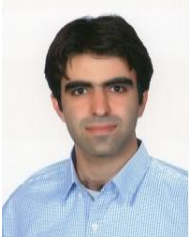

Alireza Amrollahi has a master of science in Information Technology management from University of Tehran. He is working as management consultant for different Iranian companies. His study is focused on open source software, including the role of OSS in developing countries, success of OSS and OS business models.

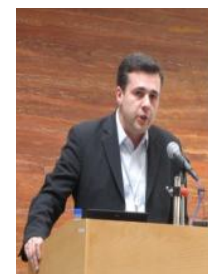

Prof Babak Akhgar graduated from Sheffield Hallam University in Software Engineering. Afterwards he gained considerable commercial experience as a Strategy Analyst and Methodology Director for several international companies. He consolidated this experience by obtaining a Masters degree (with distinction) in Information Systems in Management and a $\mathrm{PhD}$ in Information Systems. His research is on Informatics with specific focus on application of Knowledge management (KM) within security industry and e-processes (e.g. Smart Cities and e-Health) domains. 